\title{
Impact of olmesartan on blood pressure, endothelial function, and cardiovascular outcomes
}

This article was published in the following Dove Press journal:

Integrated Blood Pressure Control

27 September 2010

Number of times this article has been viewed

\section{Eduardo Pimenta' Suzanne Oparil ${ }^{2}$ \\ 'Endocrine Hypertension Research Centre and Clinical Centre of Research Excellence in Cardiovascular Disease and Metabolic Disorders, University of Queensland School of Medicine, Princess Alexandra Hospital, Brisbane, Queensland, Australia; ${ }^{2}$ Vascular Biology and Hypertension Program, University of Alabama at Birmingham, Birmingham, AL, USA}

Correspondence: Eduardo Pimenta Hypertension Unit, Princess Alexandra Hospital, 5th Floor, Ipswich Road, Woolloongabba, Brisbane, QLD, 4I02, Australia Email eduardo.pimenta@ccc.uab.edu

\begin{abstract}
The vascular endothelium, the largest "organ" in the body, synthesizes and releases a wide spectrum of vasoactive substances into the circulation. Endothelial dysfunction links hypertension and other cardiovascular (CV) risk factors that promote the development of atherosclerotic plaque, $\mathrm{CV}$ disease, and fatal and nonfatal $\mathrm{CV}$ events. Blood pressure (BP) reduction is the most effective way to reduce $\mathrm{CV}$ risk in patients with hypertension, but it is unknown whether endothelial dysfunction is a cause or consequence of hypertension. Renin-angiotensin-aldosterone system blockers improve endothelial function and have favorable vascular, metabolic, cardiac, and renoprotective effects that are independent of BP reduction. Olmesartan effectively reduces BP and also has vasoprotective properties, including reductions in endothelial dysfunction and inflammation, prevention of microalbuminuria, and reversal of vascular remodeling. Large-scale, long-term studies are needed to confirm that olmesartan has vasoprotective effects that are independent of BP control and to determine whether these pleiotropic effects translate into improved CV disease outcomes.
\end{abstract}

Keywords: hypertension, endothelial function, cardiovascular outcomes, olmesartan

\section{Introduction}

The vascular endothelium is a thin layer of cells that line the interior surface of blood vessels separating circulating blood from layers of vascular smooth muscle cells (VSMC). Since the initial description of endothelium-derived relaxing factor (EDRF) by Furchgott and Zawadzki in 1980, ${ }^{1}$ the endothelium has been considered the largest "organ" in the body. The endothelium synthesizes and releases a wide spectrum of vasoactive substances. This cellular monolayer both produces and responds to agents that regulate vascular tone, platelet aggregation, oxidative stress, inflammation, thrombogenicity, and VSMC proliferation. ${ }^{2}$ These include the vasodilators, such as nitric oxide (NO), prostacyclin, endothelium-derived hyperpolarizing factor, and carbon monoxide, and the vasoconstrictors, such as endothelin, superoxide anions $\left(\mathrm{O}_{2}^{-}\right)$, prostanoids, and angiotensin II (Ang II). Both vasodilators and vasoconstrictors are tonically active, and the balance between those factors determines the normal or pathological state of the vasculature (Figure 1).

Endothelial dysfunction is the common link between cardiovascular $(\mathrm{CV})$ risk factors, such as hypertension and diabetes, and CV diseases. ${ }^{3}$ For example, coronary vascular endothelial dysfunction independently predicts acute $\mathrm{CV}$ events in patients with and without atherosclerotic coronary artery disease. ${ }^{4}$ In this article, we discuss the relation between endothelial function, blood pressure (BP), and CV outcomes, 


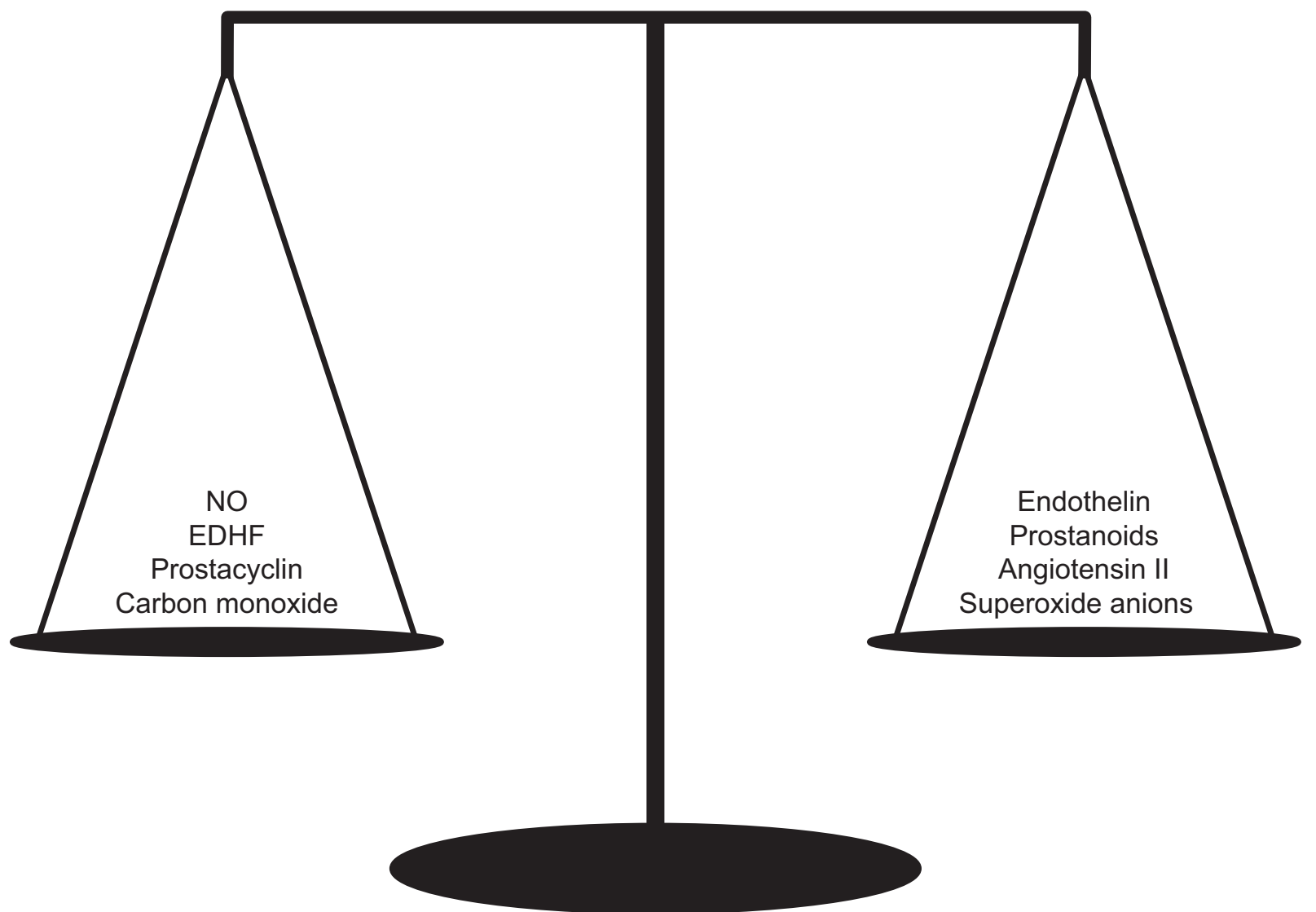

\section{Endothelial function}

Figure I Agents that act continuously in the tone regulation of the vasculature.

Abbreviations: NO, nitric oxide; EDHF, endothelium-derived hyperpolarizing factor.

with emphasis on the protective effects of the angiotensin receptor blocker (ARB) olmesartan medoxomil.

\section{Endothelial function}

\section{Nitric oxide and oxidative stress}

$\mathrm{NO}$, originally described as EDRF, ${ }^{1}$ is a free radical, shortlived, highly permeable gas. It is a potent vasodilator, inhibitor of thrombocyte aggregation and leukocyte adhesion, and suppressor of the migration and proliferation of VSMC. $\mathrm{NO}$ is released by endothelial cells in response to activation of a variety of receptors, shear stress, changes in BP, and pulsatile stretch. ${ }^{5}$ It increases intracellular cyclic guanosine monophosphate concentrations by activating guanylate cyclase, leading to VSMC relaxation. NO is synthesized by NO synthase (NOS) from L-arginine, and its formation can be inhibited by false substrates for NOS such as $\mathrm{N}^{\mathrm{G}}$-monomethyl-arginine (L-NMMA). ${ }^{6,7}$ Thus, L-NMMA can be used as an experimental tool for assessing NO function in animal models of vascular disease.
NO plays an important role in BP regulation, thrombosis, and atherosclerosis. Experimentally induced hypertension promotes the release of $\mathrm{NO}$, and decreases in $\mathrm{BP}$ suppress $\mathrm{NO}$ release, thus promoting vascular homeostasis. Inhibitors of NO production induce sustained hypertension when administered to animals, suggesting that the CV system is exposed to continuous tonic NO-dependent vasodilator tone. ${ }^{8}$

Endothelial dysfunction associated with systemic hypertension is characterized by impaired NO bioactivity related to increased oxidative stress. Oxidative stress, a condition which occurs when the production of free radicals exceeds the body's ability to neutralize and eliminate them, is believed to be a major cause of impaired NO bioactivity. Reactive oxygen species (ROS), including superoxide anions $\left(\mathrm{O}_{2}^{-}\right)$, scavenge $\mathrm{NO}$ and reduce its bioavailability. ROS are generated from both nonenzymatic and enzymatic sources. Nicotinamide adenine dinucleotide phosphate $(\mathrm{NAD}(\mathrm{P}) \mathrm{H})$ oxidase and cyclooxygenases are the major sources of $\mathrm{O}_{2}^{-} \cdot{ }^{-9}$ Thus, ROS, particularly $\mathrm{O}_{2}^{-}$, contribute to the vasoconstrictor effect of 
Ang II via their interaction with endothelium-derived NO. In addition to the scavenging effect of ROS, the reduced NO bioavailability observed in patients with hypertension compared with normotensive controls is due to a deficiency in NO synthesis (NOS activity). ${ }^{10}$

Some antihypertensive agents, such as the third generation vasodilating $\beta$ blocker nebivolol, angiotensin-converting enzyme inhibitors (ACEIs), ARBs, and calcium channel blockers (CCBs), can improve endothelial function by increasing NO bioavailability or decreasing oxidative stress. ${ }^{9}$ In addition, statins have a modest antihypertensive effect that has been attributed to potentiation of NO. ${ }^{11}$ Pharmacological inhibition of 3-hydroxy-3-methylglutaryl coenzyme A reductase with statins stimulates endothelial NOS (eNOS), attenuating the expression of caveolin-1 and reducing the abundance of caveolae in endothelial cells. Caveolin plays a role in endothelial function, binding directly to and inhibiting eNOS, thus decreasing NO availability. Thus, attenuation of caveolin expression and related stimulation of eNOS may explain the BP-reducing effect of statins.

\section{Clinical assessment of endothelial function}

Several techniques are available for the assessment of endothelial function in humans (Table 1), but all of these have limited applicability in clinical practice. The "perfect" endothelial function test should be cheap, safe, noninvasive, reproducible, repeatable, and standardized among laboratories. However, none of the tests available fulfills these requirements. ${ }^{12}$ The gold standard for diagnosing endothelial dysfunction is assessment of the response to intraarterial infusion of acetylcholine. ${ }^{3}$ However, this test is rarely used in clinical practice because of its invasive nature.

Measurement of flow-mediated vasodilation of the brachial artery by high-resolution ultrasonography is an accepted noninvasive method for assessment of endothelial function. ${ }^{13}$

Table I Methods for measuring endothelial function

Noninvasive
Ultrasound flow-mediated dilation
Flow-mediated magnetic resonance imaging
Pulse wave analysis
Pulse contour analysis
Laser doppler skin flowmetry
Pulse amplitude tonometry
Invasive
Cardiac catheterization
Venous occlusion plethysmography

The diameter of the brachial artery is measured using highresolution ultrasound before and after occlusion of the artery for 5 minutes with sphygmomanometer cuff proximal to the brachial artery (Figure 2). When the cuff is released, the reactive hyperemia causes shear stress in the artery wall and release of NO. The amount of dilation is used as a marker of the endothelial function. Maximum vasodilation capacity is induced using nitroglycerin for comparison. Although noninvasive, this test is time-consuming and operator dependent.

Endothelial dysfunction contributes to arterial stiffness (reduction of elasticity), and estimation of arterial stiffness by pulse wave analysis has been used as marker of endothelial dysfunction. Increased pulse wave velocity (PWV) and altered wave reflection are important determinants of increased systolic and pulse pressure and provide evidence of CV disease. ${ }^{14,15}$ With each ejection of blood from the left ventricle, a pressure (pulse) wave is generated and travels from the heart to the periphery at a finite speed that depends on the elastic properties of the conduit arteries. Increased arterial stiffness is correlated with elevated PWV. The pulse wave is reflected at any point of discontinuity in the arterial tree and returns to the aorta and left ventricle. The timing of the wave reflection depends on both the elastic properties and the length of the conduit arteries. Pulse wave analysis provides the augmentation index (AIx) that is a surrogate of wave reflection and is defined as augmented pressure (magnitude of wave reflection) divided by pulse pressure. ${ }^{16}$

In younger persons (Figure 3, top panel), PWV is sufficiently slow (approximately $5 \mathrm{~m} / \mathrm{s}$ ) that the reflected wave reaches the aortic valve after closure, leading to a higher diastolic BP and enhancing coronary perfusion by providing a "boosting" effect. In older persons, particularly if they are hypertensive, PWV is greatly increased (approximately $20 \mathrm{~m} / \mathrm{s}$ ) due to central arterial stiffening. At this speed, the reflective wave reaches the aortic valve before closure, leading to a higher systolic BP, pulse pressure, and afterload and a lower diastolic BP (Figure 3, bottom panel). Coronary perfusion pressure is compromised in some cases secondary to low diastolic BP.

\section{Endothelial dysfunction: from hypertension to CV disease}

Endothelial dysfunction links hypertension with other $\mathrm{CV}$ risk factors that promote the development of atherosclerotic plaque, $\mathrm{CV}$ disease, and fatal and nonfatal $\mathrm{CV}$ events (Figure 4). ${ }^{17,18}$ Multiple studies have demonstrated 

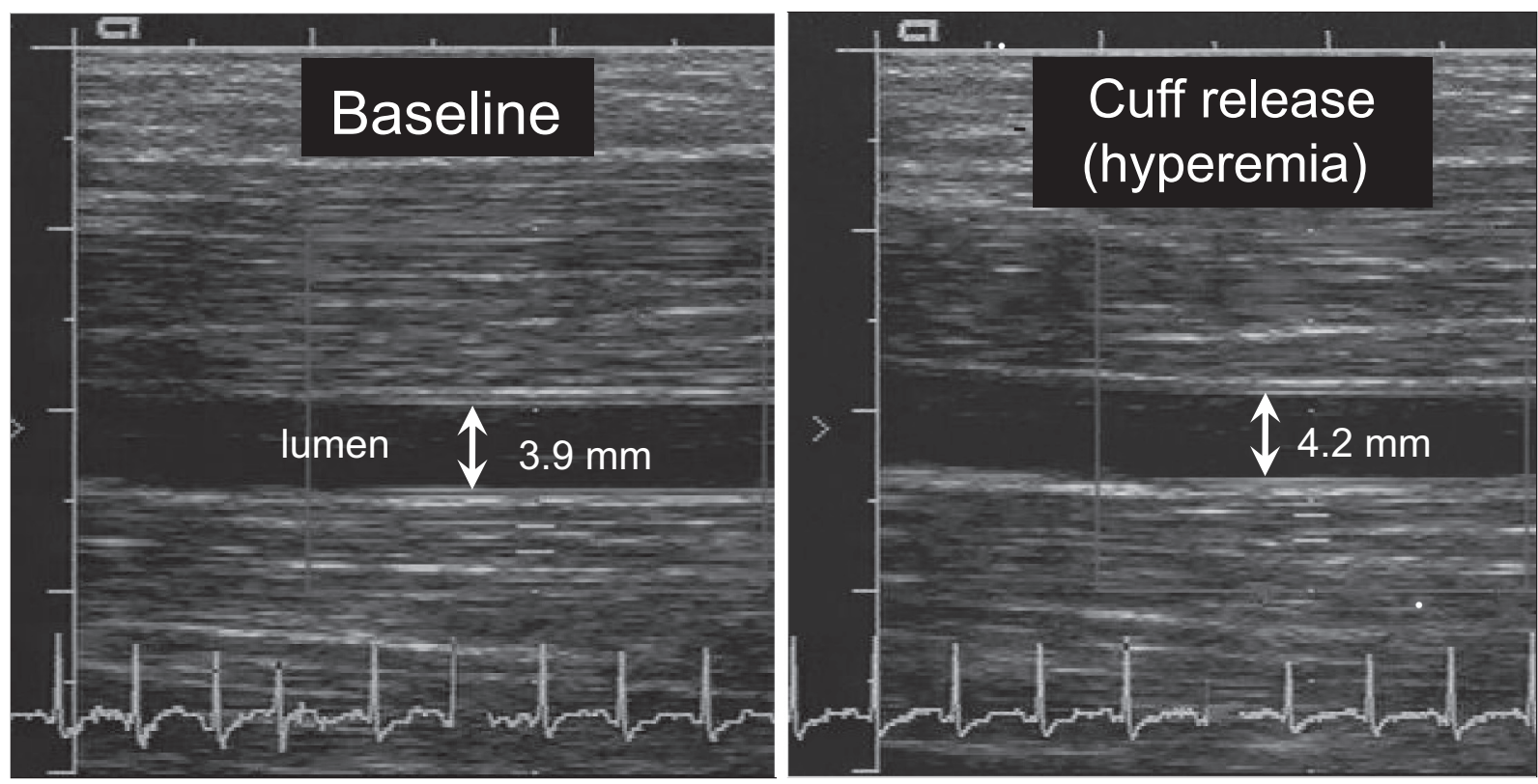

Figure 2 High-resolution ultrasound images showing the brachial artery before (left) and after (right) arterial occlusion.

impaired endothelial function in patients with hypertension. Endothelium-dependent vasodilation in response to acetylcholine infusion in the forearm and coronary circulations is impaired in patients with elevated BP. ${ }^{19-22}$ However, it is unknown whether endothelial dysfunction is a cause or consequence of hypertension. Normotensive offspring of hypertensive parents exhibits impaired endotheliumdependent vasodilatation in response to acetylcholine. ${ }^{23}$ Derangement of endothelial function in normotensive offspring of hypertensive parents is also demonstrated by decreased vasoconstriction in response to inhibition of NOS activity. ${ }^{24,25}$ Together, these findings support the
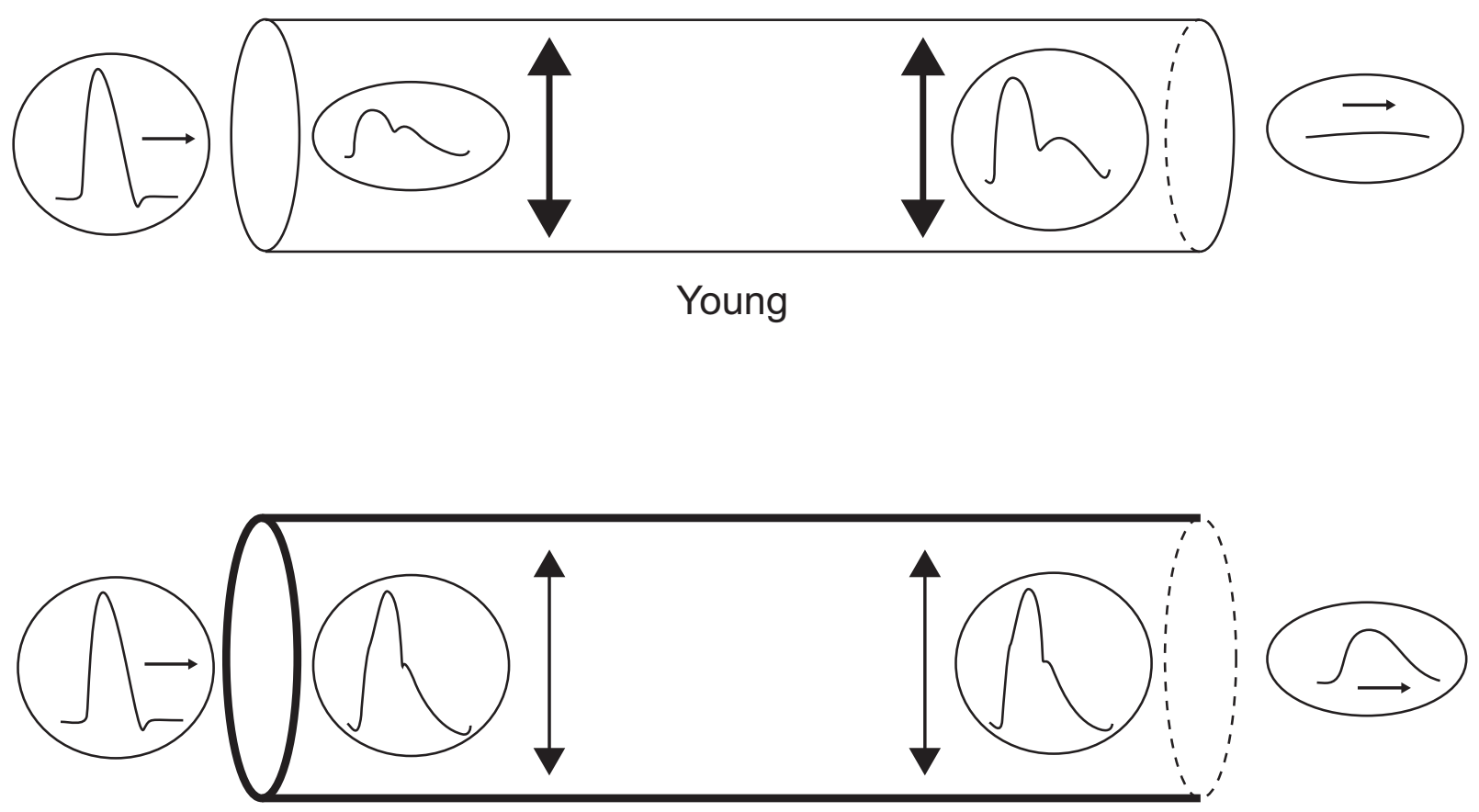

Old

Figure 3 Distensibility and pulse wave velocity (PWV). Simple tubular models of the arterial system, connecting the heart (left) to the peripheral circulation (right). Top: normal distensibility and normal PWV in a young subject. Bottom: decreased distensibility with increased PWV in an old subject. Copyright @ 2007. Reproduced with permission from O’Rourke MF, Hashimoto J. Mechanical factors in arterial aging: a clinical perspective. J Am Coll Cardiol. 2007;50(I): I-I3. 

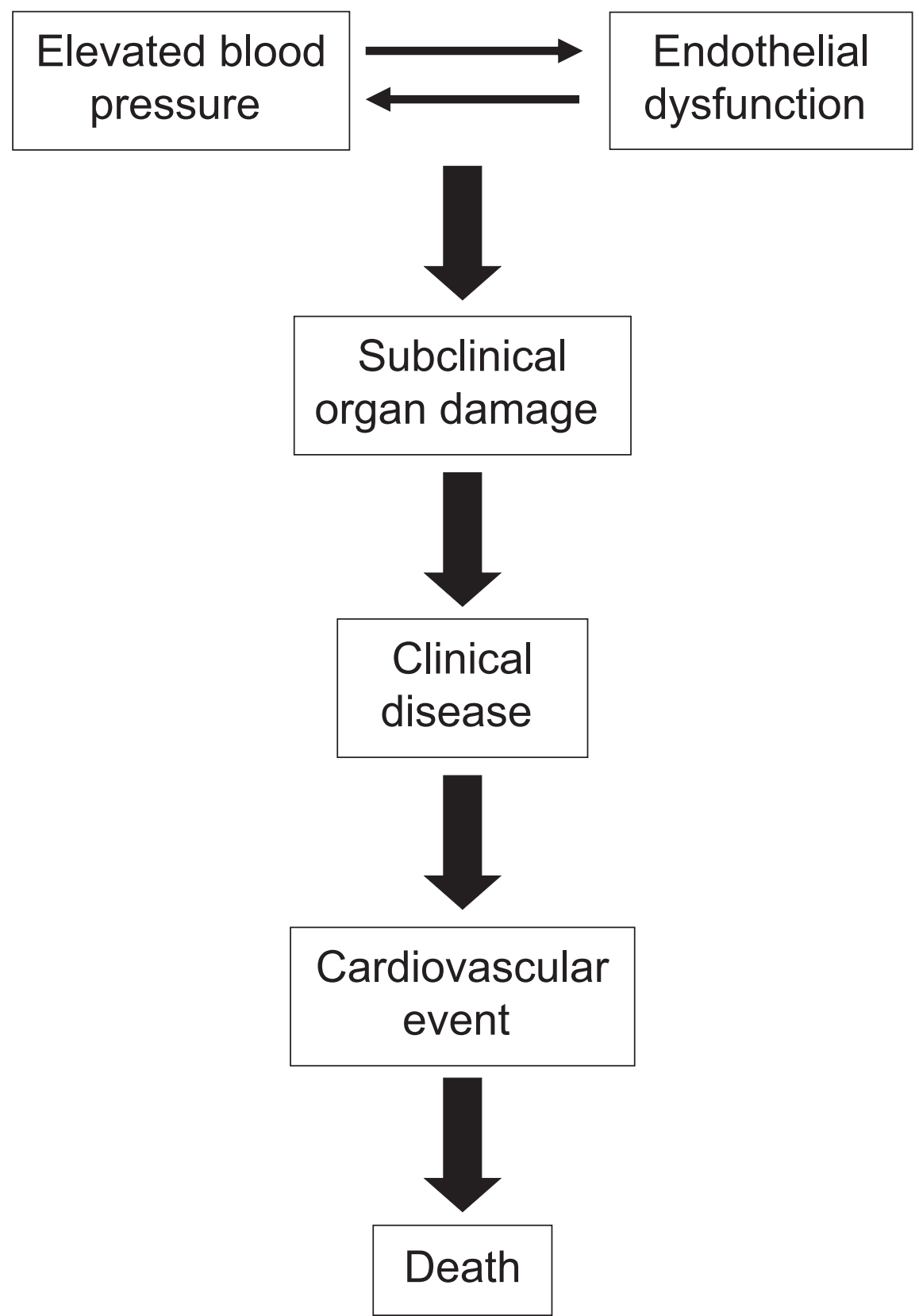

Figure 4 Cascade of events that, if not blocked, will lead to death.

interpretation that endothelial dysfunction is an antecedent rather than a consequence of hypertension.

The renin-angiotensin-aldosterone system (RAAS), the main regulator of sodium and fluid balance in normal subjects and one of the major contributors to the pathogenesis of hypertension, also plays an important role in the pathogenesis of endothelial dysfunction (Figure 5). ${ }^{26}$ Ang II increases oxidative stress by stimulating $\mathrm{NAD}(\mathrm{P}) \mathrm{H}$ oxidase, the main source of ROS in the vasculature, and accelerates senescence of endothelial progenitor cells (EPCs).$^{27} \mathrm{EPCs}$, a rare population of cells that circulate in the blood with the ability to differentiate into endothelial cells, are a marker for vascular function and cumulative $\mathrm{CV}$ risk. ${ }^{28}$ Patients with coronary artery disease have lower circulating levels of EPCs and those with hypertension have accelerated senescence of EPCs. ${ }^{29}$ This deficiency in EPC numbers/function may contribute to the development of endothelial function in these conditions.

Preclinical studies have demonstrated that activation of the Ang II type 1 (AT1) receptor contributes to the development of atherosclerosis by mediating endothelial dysfunction. Compared with wild type mice, apolipoprotein E knockout mice 


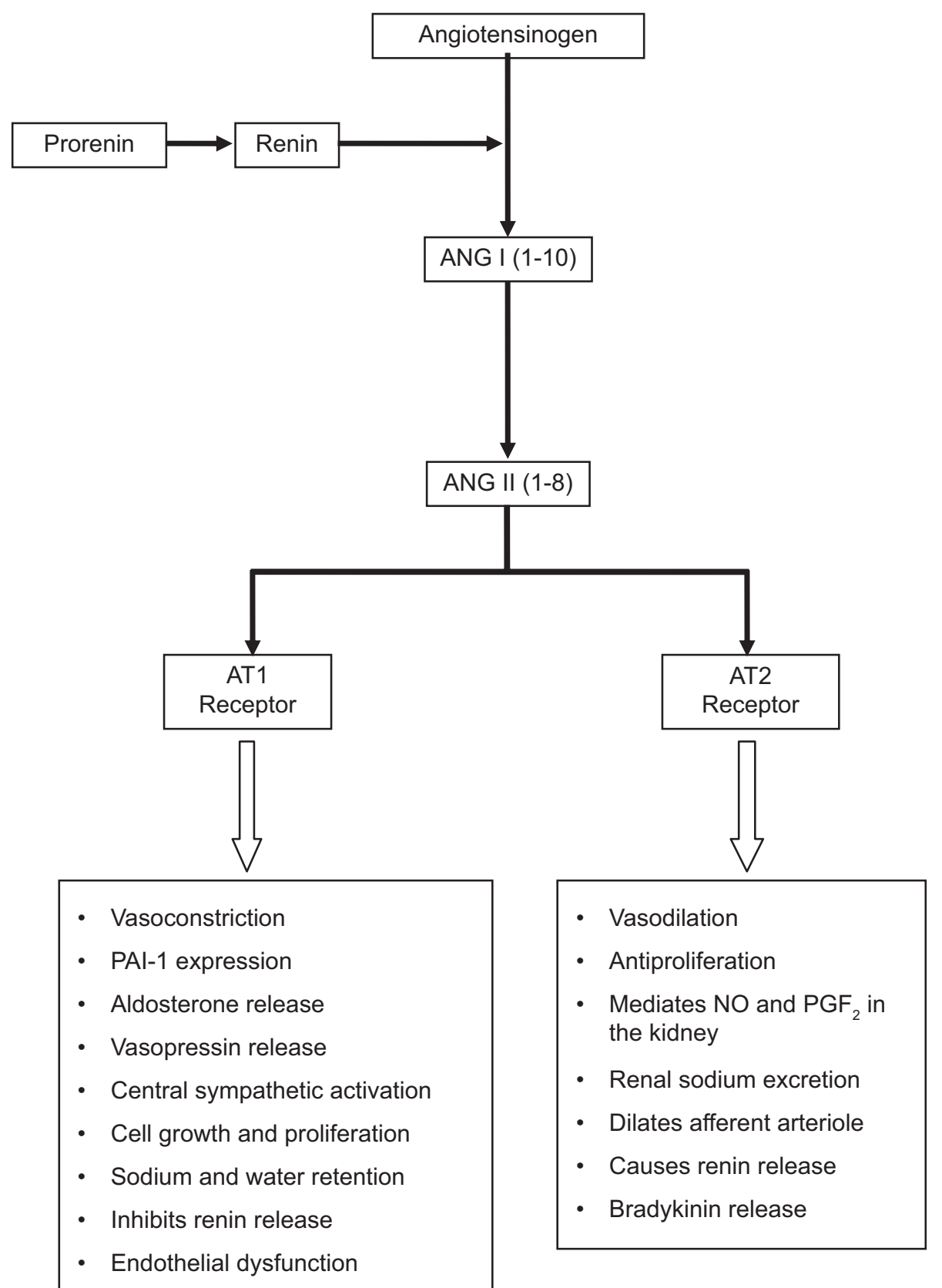

Figure 5 Mechanisms of action of angiotensin receptor blockers (ARBs).

Abbreviations: ANG I, angiotensin I; ANG II, angiotensin II; ATI, angiotensin II type I receptor; AT2, angiotensin II type 2 receptor; PAI-I, plasminogen activator inhibitor-I; NO, nitric oxide; $\mathrm{PGF}_{2}$, prostaglandin growth factor 2.

$\left(\mathrm{ApoE}^{-/-}\right)$have significantly greater $\mathrm{O}_{2}^{-}$formation, greater impairment in endothelium-dependent vasodilation, and more extensive atherosclerotic lesions development when fed a high cholesterol diet. ${ }^{30}$ In contrast, AT1 knockout mice (AT1 ${ }^{-/-}$) have lower oxidative stress, reduced endothelial dysfunction, and less atherosclerotic plaque formation than wild type mice independently of BP and plasma cholesterol levels. Offspring of ApoE $\times \mathrm{AT}^{-/-}$matings has significantly lower $\mathrm{O}_{2}^{-}$and $\mathrm{BP}$ levels than $\mathrm{ApoE}^{-/-}$mice and do not develop atherosclerosis. These findings support the functional significance of Ang II in the generation of oxidative stress and atherosclerosis in this model.

RAAS blockers improve endothelial function and have favorable vascular, metabolic, cardiac, and renoprotective effects. ARBs reduce BP by selectively blocking the binding of Ang II to the AT1 receptors in VSMC and other cell types. ${ }^{31}$ ARBs also reduce $\mathrm{CV}$ morbidity and mortality in patients with hypertension, left ventricular hypertrophy, diabetes, renal disease, and congestive heart failure. ${ }^{32-34}$ Olmesartan medoxomil is a long-acting ARB approved 
for the treatment of mild to severe hypertension that has vasoprotective properties.

\section{Olmesartan}

\section{Pharmacology}

Olmesartan medoxomil is an inactive prodrug that is rapidly and completely bioactivated by ester hydrolysis in the gut wall to the pharmacologically active compound olmesartan. Its peak plasma concentrations are achieved between 1 and 3 hours with an elimination half-life of 12-18 hours. ${ }^{35,36}$ The absolute bioavailability of olmesartan medoxomil after oral administration is $26 \%-28.6 \%$, and the steady-state plasma concentrations are reached within the first few days. Accumulation is not noted on long-term dosing. Olmesartan is excreted unchanged in the urine $(35 \%-50 \%)$ and in the bile. Olmesartan has minimal or no inhibitory activity on human cytochrome $\mathrm{P} 450 .{ }^{35,36} \mathrm{~A}$ unique mechanism of binding to the AT1 receptor appears to contribute to the sustained duration of AT1 receptor blockade seen with olmesartan. ${ }^{37,38}$ This involves the "double chain domain", whereby olmesartan binds to the receptor at two sites, a $-\mathrm{OH}$ group and an $\alpha-\mathrm{COOH}$ group, whereas other ARBs bind only at the $-\mathrm{OH}$ group. Whether the more sustained inhibition of the pressor effects of infused angiotensin seen with olmesartan compared with other ARBs is secondary to the "double chain domain" is unknown.

\section{Protective effects of olmesartan Blood pressure}

Olmesartan reduces BP rapidly and effectively in hypertensive patients. An analysis of seven randomized, double-blind, placebo- controlled, parallel group studies compared the safety $(n=2,540)$ and efficacy $(n=2,145)$ of olmesartan monotherapy with placebo in patients with essential hypertension (sitting diastolic BP $\geq 100 \mathrm{~mm} \mathrm{Hg}$ and $\leq 115 \mathrm{~mm} \mathrm{Hg}$ ). ${ }^{39}$ Olmesartan produced dose-dependent reductions in both diastolic and systolic BP within 1 week of initiating treatment, and the response was nearly maximal at 2 weeks. There was no difference in efficacy between younger $(<65$ years $)$ and older ( $>65$ years) patients.

Olmesartan reduces BP more effectively than other ARBs when administered at traditionally recommended starting doses. ${ }^{40}$ A 588 patient, multicenter, randomized, double-blind trial compared once-a-day therapy with the recommended starting doses of olmesartan (20 mg), losartan (50 mg), valsartan (80 mg), and irbesartan (150 mg) in patients with high $\mathrm{BP}$ (cuff diastolic BP $\geq 100 \mathrm{~mm} \mathrm{Hg}$ and $\leq 115 \mathrm{~mm} \mathrm{Hg}$, and a mean daytime diastolic $\mathrm{BP} \geq 90 \mathrm{~mm} \mathrm{Hg}$ and $\leq 120 \mathrm{~mm} \mathrm{Hg}$ ). A significantly greater reduction in sitting cuff diastolic BP at trough was demonstrated with olmesartan $(11.5 \mathrm{~mm} \mathrm{Hg})$ compared with losartan, valsartan, and irbesartan (8.2, 7.9, and $9.9 \mathrm{~mm} \mathrm{Hg}$, respectively, $P<0.005$ olmesartan vs losartan; $P<0.05$ olmesartan vs valsartan and irbesartan) ${ }^{41}$ Reductions in cuff systolic BP with the 4 ARBs had the same numerical trend, although differences between treatments were not statistically significant due to variability in the data. The reduction in mean 24-hour diastolic BP with olmesartan $(8.5 \mathrm{~mm} \mathrm{Hg})$ was significantly greater than reductions with losartan and valsartan (6.2 and $5.6 \mathrm{~mm} \mathrm{Hg}$, respectively, $P<0.05)$ and showed a trend toward significance when compared with irbesartan (7.4 $\mathrm{mm} \mathrm{Hg} ; P=0.087$ ) (Figure 6). The reduction in mean 24-hour systolic BP with olmesartan (12.5 mm Hg) was significantly greater than those with losartan and valsartan (9.0 and $8.1 \mathrm{~mm} \mathrm{Hg}$, respectively) and equivalent to the reduction with irbesartan (11.3 mm Hg). All drugs were well tolerated.

The differences in BP reduction achieved with olmesartan compared with losartan and valsartan are attenuated when doses of the other ARBs are increased. In a 12-week, randomized, double-blind, forced-titration study, 723 hypertensive patients were assigned to receive olmesartan $20 \mathrm{mg}$, losartan $50 \mathrm{mg}$, valsartan $80 \mathrm{mg}$, or placebo, all once daily. ${ }^{42}$ Doses were titrated to 40,100 , and $160 \mathrm{mg}$ once daily for olmesartan, losartan, and valsartan, respectively, after 4 weeks of treatment. At week 8 , doses were titrated to $50 \mathrm{mg}$ twice daily for losartan and $320 \mathrm{mg}$ once daily for valsartan. Olmesartan remained at $40 \mathrm{mg}$ once daily. Compared with placebo, all 3 medications significantly reduced mean seated diastolic BP from baseline. At week 8, patients receiving olmesartan $40 \mathrm{mg}$ once daily had significantly greater reductions in mean seated diastolic BP than those receiving losartan $(-15.2 /-12.9$ vs-10.9/-9.4 mm Hg, respectively, $P<0.001)$. There was no significant difference compared with valsartan. A significantly greater percentage of patients achieved BP goals $(<140 / 90 \mathrm{~mm} \mathrm{Hg})$ with olmesartan compared with losartan and valsartan $(39.7 \%, 19.8 \%$, and $29.0 \%$, respectively, $P<0.001$ vs losartan and $P=0.031$ vs valsartan). Olmesartan did not reduce mean seated systolic BP significantly compared with valsartan.

\section{Microalbuminuria}

Microalbuminuria is an early sign of glomerular endothelial dysfunction and is associated with progressive glomerulosclerosis, renal function loss, and development of overt proteinuria. Microalbuminuria is also associated with increased $\mathrm{CV}$ morbidity and mortality in both diabetic and nondiabetic subjects. ${ }^{43-47}$ 


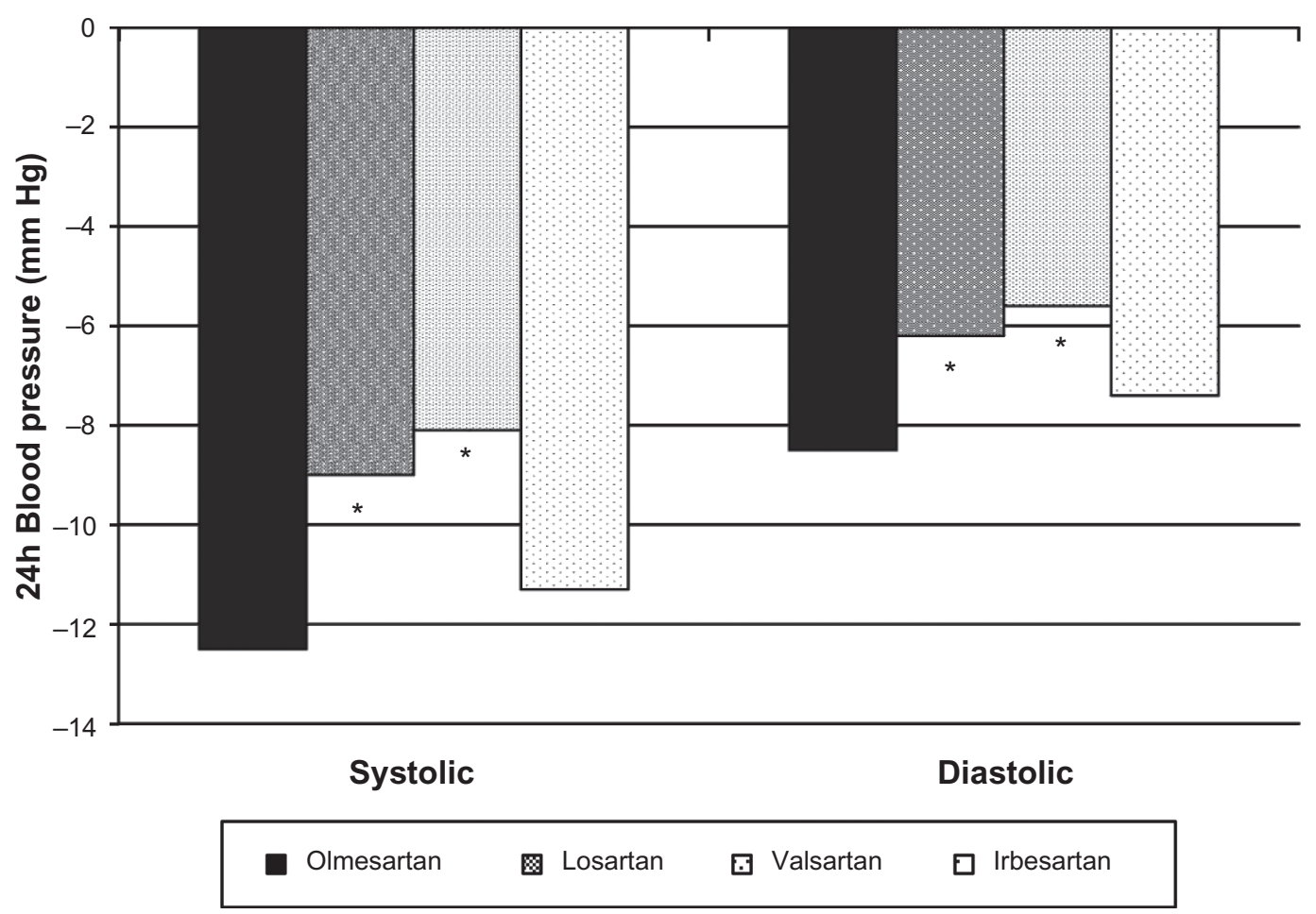

Figure 6 Reductions in mean 24-hour systolic and diastolic blood pressure with 4 different ARBs. Note: $* P<0.05$ compared with olmesartan.

The Randomized Olmesartan and Diabetes Microalbuminuria Prevention (ROADMAP) study, ${ }^{48}$ conducted in Europe, included 4,449 men and women. Participants had type 2 diabetes, normal kidney function, and at least one additional $\mathrm{CV}$ risk factor, including hypertension, but without microalbuminuria ${ }^{49}$ They were randomly assigned to receive olmesartan 40 mg daily $(n=2,232)$ or placebo $(n=2,215)$, in addition to other antihypertensive medications (except ACEIs or ARBs) during the study in order to reach the target BP of $<130 / 80 \mathrm{~mm} \mathrm{Hg}$. Primary end point was time to onset of microalbuminuria, and secondary end points included renal and CV events. The mean baseline BP was $136 / 81 \mathrm{~mm} \mathrm{Hg}$. After 48 months, nearly $80 \%$ and $71 \%$ of patients in the olmesartan and placebo groups, respectively, reached target $\mathrm{BP}(<130 / 80 \mathrm{~mm} \mathrm{Hg})$. Patients in the olmesartan group were $23 \%$ less likely than those in the placebo group to develop microalbuminuria at 48 months $(8.2 \%$ vs $9.8 \%$, hazard ratio 0.77 ; $95 \%$ confidence interval: $0.63-0.94, P=0.01)$. Overall, CV morbidity and mortality were similar (3.6\% vs $4.1 \%$ in olmesartan vs placebo), but CV deaths occurred more frequently in the olmesartan group $(\mathrm{n}=15)$ than in the placebo group ( $\mathrm{n}=3, P=0.01)$. The increased risk of $\mathrm{CV}$ mortality with olmesartan relative to placebo was attributed by the authors to possible hypotensive episodes in subjects with preexisting $\mathrm{CV}$ disease.

\section{Inflammation, vascular remodeling, and endothelial function}

Olmesartan has vasoprotective and anti-inflammatory effects that are unrelated to BP reduction. In the EUropean Trial on Olmesartan and Pravastatin in Inflammation and Atherosclerosis (EUTOPIA) study, investigators compared the anti-inflammatory effects of olmesartan alone and combined with pravastatin to placebo in patients with essential hypertension (sitting diastolic BP $\geq 95 \mathrm{~mm} \mathrm{Hg}$ and $\leq 100 \mathrm{~mm} \mathrm{Hg}$ ) and microinflammation. Microinflammation was defined as high-sensitivity C-reactive protein (CRP) $\geq 3 \mathrm{mg} / \mathrm{L}$, and detectable serum interleukin-6 (IL-6) and intercellular adhesion molecule- $1 .{ }^{50}$ Patients were randomized to olmesartan medoxomil $20 \mathrm{mg} / \mathrm{d}$ or placebo for 12 weeks. Hydrochlorothiazide $12.5-25 \mathrm{mg} / \mathrm{d}$ was added if diastolic BP $\geq 90 \mathrm{~mm} \mathrm{Hg}$. All patients received pravastatin $20 \mathrm{mg} / \mathrm{d}$ after 6 weeks of double-blind treatment for the remainder of the study. Olmesartan treatment significantly reduced serum levels of high-sensitivity CRP, high-sensitivity tumor necrosis factor- $\alpha$ (TNF- $\alpha$ ), IL-6, and monocyte chemotactic protein-1 compared with placebo independently of BP reduction. Treatment with pravastatin alone did not significantly alter inflammation markers. This study demonstrated that olmesartan significantly reduces biochemical markers of inflammation by as early as 6 weeks 
of treatment, resulting in possible additional $\mathrm{CV}$ benefits independent of BP reduction.

Olmesartan has a remedial effect on the remodeling of resistance vessels that result from hypertension-related target organ damage. The Vascular Improvement with Olmesartan medoxomil Study (VIOS) tested the hypothesis that, independent of BP control, suppression of the RAAS with olmesartan reverses abnormal remodeling of resistance vessels and has favorable effects on central hemodynamics compared with suppression of sympathetic drive with the $\beta$ blocker atenolol. ${ }^{51}$ Nondiabetic patients $(n=100)$ with stage 1 hypertension were randomized to either olmesartan $20 \mathrm{mg} / \mathrm{d}$ or atenolol $50 \mathrm{mg} / \mathrm{d}^{52}$ The doses of olmesartan and atenolol were increased to $40 \mathrm{mg}$ and $100 \mathrm{mg}$, respectively, with subsequent addition of other agents (hydrochlorothiazide, amlodipine, or hydralazine) if BP $>140 / 90 \mathrm{~mm} \mathrm{Hg}$. Subcutaneous gluteal resistance arteries were examined on a pressurized myograph to evaluate vascular structure at baseline and after 1 year of treatment. Before starting treatment, the wall width, media cross sectional area, and wall-to-lumen $(\mathrm{W} / \mathrm{L})$ ratio of resistance arteries were all significantly higher in patients with hypertension than in normotensive control subjects. In the presence of BP reduction to near normal levels in both groups, olmesartan $(n=27)$, but not atenolol $(n=22)$, significantly reduced all arteriolar dimensions. The mean $\mathrm{W} / \mathrm{L}$ ratio in patients who received olmesartan was similar to that in normotensive controls. Further, AIx, a marker of vascular stiffness and endothelial function discussed previously, fell significantly with olmesartan, but remained unchanged with atenolol. Central aortic pressure decreased significantly in both groups without differences between groups.

Endothelial function has been shown to improve with olmesartan treatment independent of BP reduction. A prospective study assessed endothelium-dependent coronary dilation in 26 untreated hypertensive patients. ${ }^{53}$ Changes of corrected myocardial blood flow $(\triangle \mathrm{MBF})$ and coronary vascular resistance $(\triangle \mathrm{CVR})$ from rest to cold pressor were measured by using 15O-water and positron emission tomography before and after 12 weeks of treatment. Patients initially received olmesartan $20 \mathrm{mg}$ or amlodipine $5 \mathrm{mg}$ daily. After $1 \mathrm{month}$, doses were doubled if BP was $>140 / 90 \mathrm{~mm} \mathrm{Hg}$, or halved if systolic BP $<110 \mathrm{~mm} \mathrm{Hg}$ to olmesartan $40 \mathrm{mg}$ or $10 \mathrm{mg}$ or amlodipine $10 \mathrm{mg}$ or $2.5 \mathrm{mg}$, respectively. Blood biomarkers, including lipids, glucose, insulin, high-sensitivity CRP, IL-6, TNF- $\alpha$, and superoxide dismutase (SOD), were also measured. Mean dose was olmesartan $27.7 \mathrm{mg}$ and amlodipine $5.6 \mathrm{mg}$ at the end of 12 weeks. $\triangle \mathrm{MBF}$ tended to be greater, and $\triangle \mathrm{CVR}$ was significantly decreased in the olmesartan group, but did not change in patients treated with amlodipine. Serum SOD activity tended to increase with olmesartan, but not with amlodipine. The authors concluded that olmesartan, but not amlodipine, improved endothelium-dependent coronary function, and that these beneficial effects of olmesartan on coronary vasomotion might be mediated via an antioxidant property of the ARB.

\section{CV outcomes}

Olmesartan has been shown to reduce the volume of atherosclerotic plaque in patients with hypertension independent of $\mathrm{BP}$ reduction. In the Multicenter Olmesartan atherosclerosis Regression Evaluation (MORE) study, carotid intima media thickness (IMT) and plaque volume were evaluated in 165 hypertensive patients (systolic/diastolic BP 140-180/90 $105 \mathrm{~mm} \mathrm{Hg}$ ) with carotid artery disease and increased CV risk. ${ }^{54}$ Carotid artery disease was defined as IMT $0.8-1.6 \mathrm{~mm}$ and at least one plaque (volume 4-500 $\mu \mathrm{L}$ ) in the common carotid artery or the carotid bulb. Patients were randomized to double-blind treatment with either olmesartan $20 \mathrm{mg} / \mathrm{d}$ or atenolol $50 \mathrm{mg} / \mathrm{d}$. Patients with uncontrolled BP $(>140 / 90 \mathrm{~mm} \mathrm{Hg}$ ) after 4 weeks of treatment were titrated to olmesartan $40 \mathrm{mg}$ or atenolol $100 \mathrm{mg}$ once daily. Hydrochlorothiazide $12.5 \mathrm{mg}$ with up-titration to $25 \mathrm{mg}$ after another 4 and 8 weeks was added, if BP remained uncontrolled. After 2 years, although both treatments reduced IMT similarly, preferential decreases in volume of larger plaques $(\geq 33.7 \mu \mathrm{L})$ were seen with olmesartan compared with atenolol ( $-11.5 \mathrm{vs}$ $+0.6 \mu \mathrm{L}, P=0.023)$. There were more men ( $73 \%$ vs $50 \%)$, current smokers (38\% vs 31\%), and patients with history of CV disease (14\% vs 9\%) in the atenolol than in the olmesartan group. The reductions in large plaques occurred despite similar reductions in BP, suggesting an antiatherosclerotic action of olmesartan that is independent of its BP lowering effect.

More recently, the results of the Impact of OLmesarten on progression of coronary atherosclerosis, evaluation by IntraVascular UltraSound (OLIVUS) study, showed that the ARB olmesartan has a positive effect on coronary atherosclerotic plaque. ${ }^{55}$ In this prospective, randomized multicenter trial, 247 patients with stable angina and native coronary artery disease underwent percutaneous coronary intervention for culprit lesions. Intravascular ultrasound (IVUS) examination was performed in the nonculprit lesions (stenosis $<50 \%$ ) before and after 12-16 months of the randomized treatment regimens. Patients were randomly assigned to control (without treatment with ACEIs or ARBs) or olmesartan 10-40 mg titrated to maximally tolerated dose by 8 weeks. Patients were also treated with a combination of $\beta$ blockers, CCBs, 
diuretics, nitrates, glycemic control agents, and/or statins per physician's guidance. Follow-up IVUS showed significantly decreased progression in total atheroma volume $(0.6 \%$ vs $5.4 \%, P<0.05)$ and percent change in percent atheroma volume $(-0.7 \%$ vs $3.1 \%, P<0.05)$ in the olmesartan compared with control group. There were no significant differences in systolic and diastolic BP between groups either at baseline or 14-month follow-up.

\section{Patient perspectives}

Adherence rate is inversely related to the number of drugs given and occurrence of adverse effects. ${ }^{56}$ Adherence to antihypertensive treatment is higher with single daily dose medication that reduces BP with low incidence of side effects. Compliance to the treatment is probably to increase if an antihypertensive agent combines these characteristics and, in addition, if patients are informed about extra protections of the medication.

\section{Conclusion}

$\mathrm{BP}$ reduction is the most effective way to reduce $\mathrm{CV}$ risk in patients with hypertension. Some antihypertensive agents have additional benefits that are independent of BP. Olmesartan effectively reduces BP and also has vasoprotective properties, including reductions in endothelial dysfunction and inflammation, prevention of microalbuminuria, and reversal of vascular remodeling. Large-scale, long-term studies are needed to confirm that olmesartan has vasoprotective effects that are independent of BP control and to determine whether these pleiotropic effects translate into improved CV disease outcomes.

\section{Disclosure}

Dr Pimenta reports no conflicts of interest in this work. Dr Oparil has received grants-in-aid from Abbott Laboratories, Astra Zeneca, Boehringer Ingelheim, Bristol Myers-Squibb, Daiichi-Sankyo, Forest Laboratories, GlaxoSmithKline, Novartis, Merck and Co, Pfizer, Sanofi-Aventis, and Schering-Plough, and has served as consultant for Bristol Myers-Squibb, Daiichi Sankyo, Merck and Co, Novartis, Pfizer, Sanofi Aventis, and The Salt Institute.

\section{References}

1. Furchgott RF, Zawadzki JV. The obligatory role of endothelial cells in the relaxation of arterial smooth muscle by acetylcholine. Nature. 1980;288(5789):373-376.

2. Deanfield JE, Halcox JP, Rabelink TJ. Endothelial function and dysfunction: testing and clinical relevance. Circulation. 2007;115(10):1285-1295.

3. Munzel T, Sinning C, Post F, Warnholtz A, Schulz E. Pathophysiology, diagnosis and prognostic implications of endothelial dysfunction. Ann Med. 2008;40(3):180-196.

4. Halcox JP, Schenke WH, Zalos G, et al. Prognostic value of coronary vascular endothelial dysfunction. Circulation. 2002;106(6):653-658.
5. Spieker LE, luscher TF. Endothelium in hypertension:nitric oxide. In: Oparil S, Weber M, editors. Hypertension: a Companion to Brenner and Rector's The Kidney. 2nd ed. Philadelphia, PA: Elsevier Saunders; 2005:146-158.

6. Palmer RM, Ashton DS, Moncada S. Vascular endothelial cells synthesize nitric oxide from L-arginine. Nature. 1988;333(6174):664-666.

7. Palmer RM, Rees DD, Ashton DS, Moncada S. L-arginine is the physiological precursor for the formation of nitric oxide in endothelium-dependent relaxation. Biochem Biophys Res Commun. 1988;153(3):1251-1256.

8. Hermann M, Flammer A, Luscher TF. Nitric oxide in hypertension. J Clin Hypertens (Greenwich). 2006;8(12 Suppl 4):17-29.

9. Brunner H, Cockcroft JR, Deanfield J, et al. Endothelial function and dysfunction. Part II: Association with cardiovascular risk factors and diseases. A statement by the Working Group on Endothelins and Endothelial Factors of the European Society of Hypertension. J Hypertens. 2005;23(2):233-246.

10. Forte P, Copland M, Smith LM, Milne E, Sutherland J, Benjamin N. Basal nitric oxide synthesis in essential hypertension. Lancet. 1997; 349(9055):837-842.

11. Feron O, Dessy C, Desager JP, Balligand JL. Hydroxy-methylglutarylcoenzyme A reductase inhibition promotes endothelial nitric oxide synthase activation through a decrease in caveolin abundance. Circulation. 2001;103(1):113-118.

12. Deanfield J, Donald A, Ferri C, et al. Endothelial function and dysfunction. Part I: Methodological issues for assessment in the different vascular beds: a statement by the Working Group on Endothelin and Endothelial Factors of the European Society of Hypertension. J Hypertens. 2005;23(1):7-17.

13. Celermajer DS, Sorensen KE, Gooch VM, et al. Non-invasive detection of endothelial dysfunction in children and adults at risk of atherosclerosis. Lancet. 1992;340(8828):1111-1115.

14. Laurent S, Cockcroft J, van Bortel L, et al. Expert consensus document on arterial stiffness: methodological issues and clinical applications. Eur Heart J. 2006;27(21):2588-2605.

15. Pimenta E, Calhoun DA, Oparil S. Etiology and pathogenesis of systemic hypertension. In: Crawford MH, DiMarco JP, Paulus WJ, editors. Cardiology. 3rd ed. Philadelphia, PA: Elsevier; 2009:511-522.

16. O'Rourke MF, Hashimoto J. Mechanical factors in arterial aging: a clinical perspective. J Am Coll Cardiol. 2007;50(1):1-13.

17. Chobanian AV, Alexander RW. Exacerbation of atherosclerosis by hypertension. Potential mechanisms and clinical implications. Arch Intern Med. 1996;156(17):1952-1956.

18. Dzau VJ, Antman EM, Black HR, et al. The cardiovascular disease continuum validated: clinical evidence of improved patient outcomes: part I: Pathophysiology and clinical trial evidence (risk factors through stable coronary artery disease). Circulation. 2006;114(25):2850-2870.

19. Linder L, Kiowski W, Buhler FR, Luscher TF. Indirect evidence for release of endothelium-derived relaxing factor in human forearm circulation in vivo. Blunted response in essential hypertension. Circulation. 1990;81(6):1762-1767.

20. Panza JA, Quyyumi AA, Brush JE Jr, Epstein SE. Abnormal endothelium-dependent vascular relaxation in patients with essential hypertension. N Engl J Med. 1990;323(1):22-27.

21. Taddei S, Virdis A, Mattei P, et al. Hypertension causes premature aging of endothelial function in humans. Hypertension. 1997;29(3): 736-743.

22. Egashira K, Suzuki S, Hirooka Y, et al. Impaired endotheliumdependent vasodilation of large epicardial and resistance coronary arteries in patients with essential hypertension. Different responses to acetylcholine and substance P. Hypertension. 1995;25(2):201-206.

23. Strawn WB, Chappell MC, Dean RH, Kivlighn S, Ferrario CM. Inhibition of early atherogenesis by losartan in monkeys with diet-induced hypercholesterolemia. Circulation. 2000;101(13):1586-1593.

24. Taddei S, Virdis A, Mattei P, Arzilli F, Salvetti A. Endotheliumdependent forearm vasodilation is reduced in normotensive subjects with familial history of hypertension. J Cardiovasc Pharmacol. 1992; 20 Suppl 12:S193-S195. 
25. McAllister AS, Atkinson AB, Johnston GD, Hadden DR, Bell PM, McCance DR. Basal nitric oxide production is impaired in offspring of patients with essential hypertension. Clin Sci (Lond). 1999;97(2): 141-147.

26. Ferrario C. Effect of angiotensin receptor blockade on endothelial function: focus on olmesartan medoxomil. Vasc Health Risk Manag. 2009;5(1):301-314.

27. Imanishi T, Hano T, Nishio I. Angiotensin II accelerates endothelial progenitor cell senescence through induction of oxidative stress. J Hypertens. 2005;23(1):97-104.

28. Hill JM, Zalos G, Halcox JP, et al. Circulating endothelial progenitor cells, vascular function, and cardiovascular risk. $N$ Engl J Med. 2003;348(7):593-600.

29. Vasa M, Fichtlscherer S, Aicher A, et al. Number and migratory activity of circulating endothelial progenitor cells inversely correlate with risk factors for coronary artery disease. Circ Res. 2001;89(1):E1-E7.

30. Wassmann S, Czech T, van Eickels M, Fleming I, Bohm M, Nickenig G. Inhibition of diet-induced atherosclerosis and endothelial dysfunction in apolipoprotein E/angiotensin II type 1A receptor double-knockout mice. Circulation. 2004;110(19):3062-3067.

31. Ruddy MC, Kostis JB. Angiotensin II receptor antagonists. In: Oparil S, Weber MA, editors. Hypertension: a Companion to Brenner and Rector's The Kidney. 2nd ed. Philadelphia, PA: Elsevier; 2005:683-704.

32. Brenner BM, Cooper ME, de Zeeuw D, et al. Effects of losartan on renal and cardiovascular outcomes in patients with type 2 diabetes and nephropathy. $N$ Engl J Med. 2001;345(12):861-869.

33. Pfeffer MA, McMurray JJ, Velazquez EJ, et al. Valsartan, captopril, or both in myocardial infarction complicated by heart failure, left ventricular dysfunction, or both. N Engl J Med. 2003;349(20):1893-1906.

34. Dahlof B, Devereux RB, Kjeldsen SE, et al. Cardiovascular morbidity and mortality in the Losartan Intervention For Endpoint reduction in hypertension study (LIFE): a randomised trial against atenolol. Lancet. 2002;359(9311):995-1003.

35. Laeis P, Puchler K, Kirch W. The pharmacokinetic and metabolic profile of olmesartan medoxomil limits the risk of clinically relevant drug interaction. J Hypertens Suppl. 2001;19(1):S21-S32.

36. Schwocho LR, Masonson HN. Pharmacokinetics of CS-866, a new angiotensin II receptor blocker, in healthy subjects. J Clin Pharmacol. 2001;41(5):515-527

37. Miura S, Fujino M, Hanzawa H, et al. Molecular mechanism underlying inverse agonist of angiotensin II type 1 receptor. J Biol Chem. 2006; 281(28):19288-19295.

38. Miura S, Kiya Y, Kanazawa T, et al. Differential bonding interactions of inverse agonists of angiotensin II type 1 receptor in stabilizing the inactive state. Mol Endocrinol. 2008;22(1):139-146.

39. Neutel JM. Clinical studies of CS-866, the newest angiotensin II receptor antagonist. Am J Cardiol. 2001;87(8A):37C-43C.

40. Oparil S, Silfani TN, Walker JF. Role of angiotensin receptor blockers as monotherapy in reaching blood pressure goals. Am J Hypertens. 2005;18(2 Pt 1):287-294.

41. Oparil S, Williams D, Chrysant SG, Marbury TC, Neutel J. Comparative efficacy of olmesartan, losartan, valsartan, and irbesartan in the control of essential hypertension. J Clin Hypertens (Greenwich). 2001;3(5): 283-291, 318 .
42. Giles TD, Oparil S, Silfani TN, Wang A, Walker JF. Comparison of increasing doses of olmesartan medoxomil, losartan potassium, and valsartan in patients with essential hypertension. $J$ Clin Hypertens (Greenwich). 2007;9(3):187-195.

43. Bianchi S, Bigazzi R, Campese VM. Microalbuminuria in essential hypertension: significance, pathophysiology, and therapeutic implications. Am J Kidney Dis. 1999;34(6):973-995.

44. Adler AI, Stevens RJ, Manley SE, Bilous RW, Cull CA, Holman RR Development and progression of nephropathy in type 2 diabetes: the United Kingdom Prospective Diabetes Study (UKPDS 64). Kidney Int. 2003;63(1):225-232.

45. Irie F, Iso H, Sairenchi T, et al. The relationships of proteinuria, serum creatinine, glomerular filtration rate with cardiovascular disease mortality in Japanese general population. Kidney Int. 2006;69(7):1264-1271.

46. Tonelli M, Jose P, Curhan G, Sacks F, Braunwald E, Pfeffer M. Proteinuria, impaired kidney function, and adverse outcomes in people with coronary disease: analysis of a previously conducted randomised trial. BMJ. 2006;332(7555):1426.

47. Ruilope L, Izzo J, Haller H, et al. Prevention of microalbuminuria in patients with type 2 diabetes: what do we know? J Clin Hypertens (Greenwich). 2010;12(6):422-430.

48. Haller H, Viberti GC, Mimran A, et al. Preventing microalbuminuria in patients with diabetes: rationale and design of the Randomised Olmesartan and Diabetes Microalbuminuria Prevention (ROADMAP) study. J Hypertens. 2006;24(2):403-408.

49. Haller H, Ito S, Izzo JL Jr, et al. Prevention of microalbuminuria in type 2 diabetes (ROADMAP Trial). J Hypertens. 2010;28 Suppl A:e233.

50. Fliser D, Buchholz K, Haller H. Antiinflammatory effects of angiotensin II subtype 1 receptor blockade in hypertensive patients with microinflammation. Circulation. 2004;110(9):1103-1107.

51. Smith RD, Yokoyama H, Averill DB, et al. The protective effects of angiotensin II blockade with olmesartan medoxomil on resistance vessel remodeling (The VIOS study): rationale and baseline characteristics. Am J Cardiovasc Drugs. 2006;6(5):335-342.

52. Smith RD, Yokoyama H, Averill DB, Schiffrin EL, Ferrario CM. Reversal of vascular hypertrophy in hypertensive patients through blockade of angiotensin II receptors. J Am Soc Hypertens. 2008;2(3):165-172.

53. Naya M, Tsukamoto T, Morita K, et al. Olmesartan, but not amlodipine, improves endothelium-dependent coronary dilation in hypertensive patients. J Am Coll Cardiol. 2007;50(12):1144-1149.

54. Stumpe KO, Agabiti-Rosei E, Zielinski T, et al. Carotid intima-media thickness and plaque volume changes following 2-year angiotensin IIreceptor blockade. The Multicentre Olmesartan atherosclerosis Regression Evaluation (MORE) study. Ther Adv Cardiovasc Dis. 2007;1(2):97-106.

55. Hirohata A, Yamamoto K, Miyoshi T, et al. Impact of olmesartan on progression of coronary atherosclerosis: a serial volumetric intravascular ultrasound analysis from the OLIVUS (impact of OLmesarten on progression of coronary atherosclerosis: evaluation by intravascular ultrasound) trial. J Am Coll Cardiol. 2010;55(10):976-982.

56. Pimenta E, Oparil S. Fixed combinations in the management of hypertension: patient perspectives and rationale for development and utility of the olmesartan-amlodipine combination. Vasc Health Risk Manag 2008;4(3):653-664.

Integrated Blood Pressure Control

\section{Publish your work in this journal}

Integrated Blood Pressure Control is an international, peer-reviewed open-access journal focusing on the integrated approach to managing hypertension and risk reduction. Treating the patient and comorbidities together with diet and lifestyle modification and optimizing healthcare resources through a multidisciplinary team approach constitute key

\section{Dovepress}

features of the journal. This journal is indexed on American Chemical Society's Chemical Abstracts Service (CAS). The manuscript management system is completely online and includes a very quick and fair peerreview system, which is all easy to use. Visit http://www.dovepress.com/ testimonials.php to read real quotes from published authors. 